\title{
ANALISIS DETERMINAN YANG BERHUBUNGAN DENGAN PEMILIHAN ALAT KONTRASEPSI OLEH AKSEPTOR KB DI PMB TUTI GAMBUT KABUPATEN BANJARKALIMANTAN SELATAN
}

\author{
(Determinant Analysis Related to Contraceptive Device Selection by Acceptor at \\ Independent Practice Tuti Gambut, Banjar Regency, South Kalimantan)
}

\author{
Mirawati, Rr. Sri Nuriaty, Darmayanti Wulandatika \\ Fakultas Keperawatan dan Ilmu Kesehatan, \\ Universitas Muhammadiyah Banjarmasin \\ Email :19mirawati@gmail.com, putriajo96@gmail.com, darmadatika@gmail.com
}

\begin{abstract}
ABSTRAK
Jumlah akseptor kontrasepsi MKJP lebih rendah dibandingkan non MKJP. Rendahnya angka pengguna MKJP ini dinilai menimbulkan beberapa permasalahan seperti tingginya angka kegagalan penundaan atau penjarangan memiliki anak.Pemilihan metode kontrasepsi ini tentunya dapat dipengaruhi oleh beberapa faktor.Tujuan penelitian ini adalah menentukan determinan yang berhubungan dengan pemilihan alat kontrasepsi pada akseptor KB di PMB Tuti Gambut Kabupaten Banjar Kalimantan Selatan. Penelitian ini menggunakan desain cross sectional dengan desain penelitian analitik.Populasi dalam penelitian ini adalah seluruh akseptor KB di PMB Tuti Gambut. Penelitian ini menggunakan tehnik simple random sampling dan didapatkan sampel yang diambil adalah sejumlah 75 orang.Tehnik pengambilan data menggunakan data sekunder, analisis data dilakukan dengan menggunakan uji chi square. Hasil penelitian ini yaitu dari segi usia akseptor KB yang ada di PMB Tuti terbanyak adalah pada usia tidak berisiko (usia reproduktif) yaitu usia 20 sampai 35 tahun. Akseptor dengan paritas yang tidak berisiko lebih banyak dari pada akseptor yang memiliki paritas yang berisiko (paritas lebih dari 3), sedangkan akseptor yang berpendidikan tinggi lebih sedikit dari pada akseptor yang memiliki pendidikan rendah.Akseptor yang menggunakan alat kontrasepsi jangka panjang lebih sedikit dibandingkan dengan akseptor yang menggunakan kontrasepsi non MKJP. Faktor determinan yang berhubungan dalam pemilihan kontrasepsi MKJP adalah usia, sedangkan faktor paritas dan pendidikan tidak berhubungan dengan pemilihan kontrasepsi MKJP.
\end{abstract}

\section{Kata kunci : Program Keluarga Berencana, Akseptor KB, Determinan ABSTRACT}

The number of Long-Term contraceptive method contraceptive acceptors are lower than Long-Term contraceptive method contraceptive. The small amount of Long-Term contraceptive method contraceptive users is considered to cause several problems such as the high rate of failure to delay or to thin to have children. The choice of contraceptive method positively can be influenced by several factors. This study was to determine the determinants associated with the selection of contraceptives in family planning acceptors in the independent practice Tuti Gambut of Banjar Regency, South Kalimantan. This study used a crosssectional design with analytical research design. The population in this study were all family planning acceptors in the independent practice Tuti Gambut. This study used a simple random sampling technique and found that the samples taken were 75 people. The method of retrieving data uses secondary data. Data analysis is done using the chi-square test. The results of this study are in terms of the age of family planning acceptors in the most independent practice Tuti is at the age of not at risk (reproductive age), namely the period of 20 to 35 years. Acceptors with parity that are not at higher risk than acceptors who have risky equality (parity more than 3 ), while acceptors who are highly educated are less than acceptors who have low education.Accepters who use long-term contraceptives are less than acceptors who use nonLong-Term contraceptive method contraceptive contraception. The determinant factors related to the selection of MKJP contraception are age, while the parity and education factors are not associated with Long-Term contraceptive method contraceptive contraception selection.

\section{Keywords: Family Planning Program; Acceptors of contraceptive; Determinant PENDAHULUAN}


Penduduk merupakan modal pembangunan. Dalam pembangunan, penduduk dapat menjadi aset ataupun beban. Jumlah penduduk yang besar hanya akan menjadi aset jika disertai dengan kualitas sumber daya yang baik. Di sisi lain, jumlah penduduk yang terlampau sedikit dapat menjadi masalah bagi keberlangsungan jumlah penduduk di masa depan. Oleh karena itu, angka kelahiran total (Total Fertility Rate) menjadi sasaran strategis yang harus diperhatikan dari waktu ke waktu. Angka kelahiran merupakan salah satu komponen pertumbuhan penduduk yang bersifat menambah jumlah penduduk. Melalui sasaran strategis ini, BKKBN memastikan membuat kegiatan-kegiatan strategis yang fokus pada pengendalian jumlah penduduk.

Penggunaan kontrasepsi merupakan salah satu upaya dalam Program KKBPK untuk pengendalian fertilitas atau menekan pertumbuhan penduduk yang paling efektif. Dalam pelaksanaannya diupayakan agar semua metode kontrasepsi yang disediakan dan ditawarkan kepada masyarakat memberikan manfaat optimal dengan meminimalkan efek samping maupun keluhan yang ditimbulkan. Metode kontrasepsi dapat dibedakan menjadi dua yaitu metoda kontrasepsi jangka panjang (MKJP) dan metoda kontrasepsi jangka pendek/non MKJP. Alat dan obat ini memiliki tingkat efektivitas yang lebih tinggi dibandingkan non MKJP dalam hal pencegahan kehamilan (Laporan Kinerja BKKBN, 2017).

Keluarga berencana merupakan salah satu strategi untuk mengurangi kematian ibu khususnya ibu dengan kondisi 4T yaitu Terlalu muda melahirkan (di bawah usia 20 tahun), Terlalu sering melahirkan, Terlalu dekat jarak melahirkan, dan Terlalu tua melahirkan (di atas usia 35 tahun). Selain itu, program KB juga bertujuan untuk meningkatkan kualitas keluarga agar dapat timbul rasa aman, tentram, dan harapan masa depan yang lebih baik dalam mewujudkan kesejahteraan lahir dan kebahagiaan batin. KB juga merupakan salah satu cara yang paling efektif untuk meningkatkan ketahanan keluarga, kesehatan, dan keselamatan ibu, anak, serta perempuan. Pelayanan KB meliputi penyediaan informasi, pendidikan, dan cara-cara bagi keluarga untuk dapat merencanakan kapan akan mempunyai anak, berapa jumlah anak, berapa tahun jarak usia antara anak, serta kapan akan berhenti mempunyai anak (Profil Kesehatan Indonesia, 2017).

Faktor paling penting dalam upaya program keluarga berencana adalah dengan pemilihan alat kontrasepsi yang benar. Pemilihan kontrasepsi berdasarkan efektivitasnya dikategorikan menjadi dua pilihan metode kontrasepsi seperti suntik, pil, dan kondom yang termasuk dalam katagori non metode kontrasepsi jangka panjang (non MKJP) dan katagori metode kontrasepsi jangka panjang (MJKP) seperti IUD, implant, MOW, dan MOP (Manuaba, 2010).

Beberapa faktor yang dapat mempengaruhi seorang perempuan dalam memilih alat kontrasepsi, adalah tingkat pendidikan, pengetahuan, ekonomi, tarif pelayanan, persetujuan pasangan, budaya oleh karena itu tenaga kesehatan diharapkan mampu memberikan Komunikasi Informasi dan Edukasi (KIE) yang lebih efektif kepada calon akseptor KB (Handayani, 2010).

KB aktif di antara PUS tahun 2017 sebesar $63,22 \%$, sedangkan yang tidak pernah ber-KB sebesar 18,63\%. KB aktif tertinggi terdapat di Bengkulu yaitu sebesar $71,98 \%$ dan yang terendah di Papua sebesar 25,73\%. Terdapat lima provinsi dengan cakupan KB aktif kurang dari $50 \%$ yaituPapua, Papua Barat, Nusa Tenggara Timur, Maluku, dan Kepulauan Riau. Berdasarkan pola dalam pemilihan jenis alat kontrasepsi sebagian besar peserta KB Aktif memilih suntikan dan pil sebagai alat kontrasepsi bahkan sangat dominan (lebih dari 80\%) dibanding metode lainnya; suntikan $(62,77 \%)$ dan pil $(17,24 \%)$. Padahal suntikan dan pil termasuk dalam metode kontrasepsi jangka pendek sehingga tingkat efektifitas suntikan dan pil dalam pengendalian kehamilan lebih rendah dibandingkan jenis kontrasepsi lainnya.

Dari data tersebut juga dapat diketahui bahwa partisipasi laki-laki dalam ber-KB masih sangat rendah, yaitu pada MOP sebanyak 0,53\% dan Kondom sebanyak 1,22\% Penggunaan MKJP (Metode Kontrasepsi Jangka Panjang) masih sangat rendah dikarenakan pengetahuan masyarakat yang masih rendah tentang kelebihan metode MKJP dan keterbatasan jumlah tenaga terlatih serta sarana yang ada. Dari keseluruhan jumlah peserta KB aktif, hanya 17,45\% diantaranya yang menggunakan KB MKJP. Sedangkan $81,23 \%$ lainnya pengguna $K B$ non MKJP dan 1,32\% menggunakan metode KB tradisional. Berdasarkan metode $\mathrm{KB}$, provinsi tertinggi dengan peserta KB MKJP tertinggi 
terdapat di Bali $(39,14 \%)$, D.I Yogyakarta $(36,03 \%)$, dan Nusa Tenggara Timur $(30,49)$. Sedangkan Kalimantan Tengah dan Kalimantan Selatan walaupun secara keseluruhan merupakan provinsi dengan cakupan KB aktif yang tinggi, namun pengguna MKJP yang sangat rendah (Profil Kesehatan Indonesia, 2017).

Persentase Wanita Berumur 15-49 tahun yang berstatus kawin dan menggunakan KB di Provinsi Kalimantan Selatan pada tahun 20122017 adalah sebagai berikut pada tahun 2012 sebesar 70,02 persen, tahun 2013 sebesar 69,91 persen, pada tahun 2014 sebesar 70,80 persen, pada tahun 2015 sebesar 70,13 persen, pada tahun 2016 sebesar 69,78 persen dan pada tahun 2017 sebesar 67,59 persen (BPS, 2018).

Menurut Hasil Survei Demografi dan Kesehatan (SDKI) tren pemakaian kontrasepsi pada wanita kawin usia 15-49 tahun yaitu menurut data SDKI 2012 sebesar 61,9 persen, dan meningkat pada tahun 2017 sebesar 63,6 persen. Status pemakaian kontrasepsi dan jenis yang mereka pakai pada tahun 2017 adalah sebesar 63, 6 persen memakai alat kontrasepsi yang terdiri dari sebanyak 29,0 persen suntik KB, 12,2 peren pil, 4,7 persen implant , 4,7 persen IUD, 4,2 persen senggama terputus, 3,7 persen MOW, 2,5 persen kondom, 1,9 persen pantang berkala, 0,2 persen MDP dan 0,1 persen MAL (SDKI, 2017).

Berdasarkan data di atas, peneliti tertarik untuk meneliti analisis determinan yang berhubungan dengan pemilihan alat kontrasepsi oleh akseptor KB.

\section{METODE PENELITIAN}

Penelitian ini menggunakan desain cross sectional dengan desain penelitian analitik karena peneliti bertujuan untuk mengetahui hubungan antar variabel dimana variabel independen dan variabel dependen diidentifikasi pada satu waktu (creswell, 2016).

Peneliti menggunakan pendekatan secara cross sectional karena peneliti bermaksud mengidentifikasi faktor determinan apa saja yang berhubungan dengan pemilihan alat kontrasepsi jangka panjang oleh akseptor. Jumlah populasi adalah 92 orang yaitu seluruh akseptor KB di PMB Tuti Gambut Kabupaten Banjar Kalimantan Selatan. Penelitian ini menggunakan tehnik simple random sampling dan didapatkan sampel yang diambil adalah sejumlah 75 orang. Tehnik pengambilan data menggunakan data sekunder, analisis data dilakukan dengan menggunakan uji chi square untuk menganalisis hubungan antar variabel.

\section{HASIL DAN PEMBAHASAN}

Hasil yang diperoleh dalam penelitian ini mengenai determinan yang berhubungan dengan pemilihan alat kontrasepsi yaitu ada faktor usia, paritas dan pendidikan adalah sebagai berikut:

Tabel 1. Faktor Determinan Pemilihan Kontrasepsi MKJP di PMB Tuti Gambut

\begin{tabular}{lc}
\hline \multicolumn{1}{c}{ Variable } & $\mathbf{n ~ ( \% )}$ \\
\hline & \\
Usia & \\
Risiko & 10,7 \\
Tidak risiko & 89,3 \\
Paritas & \\
Risiko & \\
Tidak risiko & 24 \\
& 76 \\
Pendidikan & \\
Rendah & \\
Tinggi & 90,7 \\
Kontrasepsi & 9,3 \\
MKJP & \\
Non MKJP & 20 \\
\hline
\end{tabular}

Dari hasil penelitian diatas terlihat bahwa dari segi usia akseptor KB yang ada di PMB Tuti terbanyak adalah pada usia tidak berisiko (usia reproduktif) yaitu usia 20 sampai 35 tahun.

Akseptor dengan paritas yang tidak berisiko lebih banyak daripada akseptor yang memiliki paritas yang berisiko (paritas lebih dari 3 ), sedangkan akseptor yang berpendidikan tinggi lebih sedikit daripada akseptor yang memiliki pendidikan rendah.

Akseptor yang berpendidikan tinggi adalah lulusan D. 3, dan S1.Akseptor yang menggunakan alat kontrasepsi jangka panjang lebih sedikit dibandingkan dengan akseptor yang menggunakan kontrasepsi non MKJP.

Hasil penelitian ini sesuai dengan hasil survey pada profil kesehatan Indonesia tahun 2017 yang mengatakan bahwa pengguna alat kontrasepsi di Indonesia masih sangat sedikit.

Hasil penelitian ini menunjukkan bahwa akseptor lebih banyak memilih alat kontrasepsi yang non MKJP sedangkan kontrasepsi MKJPmemiliki tingkat efektivitas yang lebih tinggi dibandingkan non MKJP dalam hal pencegahan kehamilan (Laporan Kinerja BKKBN, 2017). 


\section{Analisis Bivariat}

1. Hubungan usia dengan pemilihan kontrasepsi MKJP

Tabel 2. Usia Responden dengan Pemilihan Kontrasepsi MKJP di PMB Tuti Gambut

\begin{tabular}{llll}
\hline Usia & \multicolumn{2}{l}{ Kontrasepsi $(\%)$} & P Value \\
\hline & MKJP & Non MKJP & \\
Risiko & 6,7 & 26,7 & 0,025 \\
Tidak Risiko & 93,3 & 73,3 & \\
Total & 100 & 100 & \\
\hline
\end{tabular}

Hasil penelitian ini menunjukkan adanya hubungan yang signifikan antara usia dengan pemilihan kontrasepsi MKJP signifikansi ini berdasarkan chisquare hitung yaitu sebesar $(p=0.025)$.

Menurut Hartanto (2004), pola dasarnya penggunaan kontrasepsi yang rasional pada usia diantara 20-30 tahun adalah kontrasepsi yang mempunyai reversibilitas yang tinggi karena pada usia tersebut pasangan usia subur masih berkeinginan untuk mempunyai anak. Periode usia istri antara 20-30/35 tahun merupakan periode usia paling baik untuk melahirkan, dengan jumlah anak 2 orang dan jarak antara kelahiran adalah 2-4 tahun.

Menurut Notoatmodjo (2010) perilaku seseorang termasuk dalam pemilihan alat kontrasepsi dipengaruhi oleh usia. Peluang lebih kecil untuk menggunakan metode MKJP dimiliki oleh wanita usia muda dibandingkan dengan yang tua.

Hasil penelitian ini sejalan dengan hasil penelitian Putri (2017) yang mengatakan bahwa faktor umur lebih berhubungan dengan pemilihan kontrasepsi MKJP dari pada paritas. Hasil penelitian ini juga sejalan dengan hasil survey RISKESDAS (2012) yang menyebutkan bahwa wanita usia subur lebih memilih menggunakan kontrasepsi non MKJP.

2. Hubungan paritas dengan pemilihan kontrasepsi MKJP

Tabel 3. Paritas Responden dengan Pemilihan Kontrasepsi MKJP di PMB Tuti Gambut

\begin{tabular}{llll}
\hline Paritas & \multicolumn{2}{l}{ Kontrasepsi $(\%)$} & P Value \\
\hline & MKJP & Non MKJP & \\
Risiko & 23,3 & 26,7 & 0,78 \\
Tidak Risiko & 76,7 & 73,3 & \\
Total & 100 & 100 & \\
\hline
\end{tabular}

Hasil penelitian ini tidak menunjukkan adanya hubungan yang signifikan antara paritas dengan pemilihan kontrasepsi MKJP signifikansi ini berdasarkan chisquare hitung yaitu sebesar $(p=0.78)$.

Hasil penelitian ini sejalan dengan penelitian Lontaan tahun 2014 bahwa tidak ada hubungan antara paritas dengan pemilihan jenis kontrasepsi.Penelitian tersebut menunjukkan bahwa tidak selalu pemilihan kontrasepsi berhubungan dengan faktor jumlah anak, hal ini dapat dipengaruhi oleh karakteristik dan jumlah responden penelitian.

Paritas atau jumlah anak harus di perhatikan setiap keluarga karena semakin banyak anak semakin banyak pula tanggungan kepala keluarga dalam mencukupi kebutuhan materiil dan menjaga kesehatan sistem reproduksi karena semakin sering melahirkan kesehatan ibu akan semakin rentan (Wiknjojosastro, 2005).

3. Hubungan pendidikan dengan pemilihan kontrasepsi MKJP

Tabel 4. Pendidikan Responden dengan Pemilihan Kontrasepsi MKJP di PMB Tuti Gambut

\begin{tabular}{llll}
\hline Pendidikan & \multicolumn{2}{l}{ Kontrasepsi $(\%)$} & P Value \\
\hline & MKJP & Non MKJP & \\
Rendah & 90 & 93,3 & 0,69 \\
Tinggi & 10 & 6,7 & \\
Total & 100 & 100 & \\
\hline
\end{tabular}

Hasil penelitian ini tidak menunjukkan adanya hubungan yang signifikan antara pendidikan dengan pemilihan kontrasepsi MKJP signifikansi ini berdasarkan chisquare hitung yaitu sebesar $(p=0.69)$.

Hasil penelitian ini sejalan dengan hasil penelitian Afsari (2017) yang mengatakan bahwa faktor pendidikan tidak berpengaruh terhadap pemilihan kontrasepsi. Pendidikan tidak berpangaruh dalammenentukan ke ikut sertaan ibu menjadi akseptor KB dalam menentukan pilihankontrasepsi apa yang ingin digunakan. Pendidikan rendah tidak mutlak memiliki pengetahuan atau informasi yang rendah pula sebab, informasi tidakhanya dapat diperoleh secara formal saja tetapi juga non formal.

Secara teori, pendidikan seseorang dapat mendukung atau mempengaruhi tingkat pengetahuan dan taraf pendidikan yang rendah akan sulit menerima informasi dan tidak tahu bagaimana cara dalam 
menentukan dan memilih kontrasepsi yang sesuai baginya (Brahm, 2007). Namun pada zaman sekarang, pengetahuan seseorang itu tidak tergantung pada pendidikannya tetapi dapat diperoleh dari informasi-informasi media dan informasi dari orang sekitar, sehingga hal tersebut sangat berpengaruh terhadap apa yang mereka putuskan khususnya pada keputusan untuk memilih menggunakan kontrasepsi.

\section{KESIMPULAN}

Hasil penelitian ini yaitu dari segi usia akseptor KB yang ada di PMB Tuti terbanyak adalah pada usia tidak berisiko (usia reproduktif) yaitu usia 20 sampai 35 tahun.

Akseptor dengan paritas yang tidak berisiko lebih banyak daripada akseptor yang memiliki paritas yang berisiko (paritas lebih dari 3 ), sedangkan akseptor yang berpendidikan tinggi lebih sedikit daripada akseptor yang memiliki pendidikan rendah.

Akseptor yang berpendidikan tinggi adalah lulusan D. 3, dan S1.Akseptor yang menggunakan alat kontrasepsi jangka panjang lebih sedikit dibandingkan dengan akseptor yang menggunakan kontrasepsi non MKJP.

Faktor determinan yang berhubungan dalam pemilihan kontrasepsi MKJP adalah usia, sedangkan faktor paritas dan pendidikan tidak berhubungan dengan pemilihan kontrasepsi MKJP.

Bagi tenaga kesehatan diharapkan agar dapat memberikan KIE kepada masyarakat agar dapat memilih metode MKJP yang lebih efektif daripada non MKJP. Bagi masyarakat diharapkan agar dapat lebih giat mencari tahu informasi mengenai alat kontrasepsi yang efektif.

\section{DAFTAR PUSTAKA}

Afsari, Sitti. 2017. Faktor Yang mempengaruhi Akseptor KB dalam memilih Kontrasepsi di Puskesmas Jumpandang Baru Makassar. Skripsi. Fakultas Kedokteran dan IImu Kesehatan UIN Alauddin Makassar.

Badan Pusat Statistik. 2018. Statistik Indonesia Statistical Yearbook of Indonesia 2018. Jakarta: Badan Pusat Statistik.

BKKBN. 2018. Laporan Kinerja BKKBN, 2017. Jakarta : BKKBN.
Brahm. 2007. Ragam Metode Kontrasepsi. Jakarta: EGC.

Creswell, Jhon W. 2016. Research Design Pendekatan Kulalitatif, Kuantitatif dan Mixed. Yogyakarta: Pustaka Belajar.

Handayani, S. 2010. Buku Ajar Pelayanan Keluarga Berencana. Yogyakarta:Pustaka Rihama.

Hartanto, H. 2004.Keluarga Berencana Dan Kontrasepsi. Jakarta: Pustaka Sinar Harapan.

KEMENKES. 2018. Profil Kesehatan Indonesia 2017. Jakarta: Kementerian Kesehatan RI.

Lontaan, Anita., Kusmiyati., Dompas, Robin. 2014. Faktor - Faktor Yang Berhubungan Dengan Pemilihan Kontrasepsi Pasangan Usia Subur Di Puskesmas Damau Kabupaten Talaud. Jurnal IImiah Bidan Vol 2 No 1 JanuariJuni 2014.

Manuaba. 2010. IImu Kebidanan Penyakit Kandungan dan KB. Jakarta : EGC.

Notoatmodjo. 2010. IImu Perilaku Kesehatan. Jakarta: Rineka Cipta.

Putri dan Menik. 2017. Hubungan usia dan paritas dengan penggunaan metode kontrasepsi jangka panjang pada akseptor baru di puskesmas lendah 1 kulon progo Yogyakarta. UNISA: Yogyakarta.

Riset Kesehatan Dasar Tahun 2012.

Survei Demografi dan Kesehatan Indonesia Tahun 2012.

Survei Demografi dan Kesehatan Indonesia Tahun 2017.

Wiknojosastro, G. 2005. Panduan Praktis Pelayanan Kontrasepsi. Jakarta: YBPSP. 